\title{
Study on Application of Virtual Reality in Film Art
}

\author{
Yue Wu \\ School Of Communications, Liyi University, Liyi 276001, China \\ paperiset@163.com
}

Keywords: Virtual reality, virtual image technology, film art, movie scene.

\begin{abstract}
This paper analysis and elaborate how digital virtual technology have a tremendous impact on the cinematic art form after it apply to the film art, which based on current image status of contemporary arts, cut into research from the perspective of the relationship between technology and art, and listed many movie scenes as illustration and reference. The virtual technology opened a world that full of magic and magical for artistic creation, changed the traditional art of film style, and also made the movie even more interesting and vividly in order to attract lots of audience. We have enough reason and faith to believe that the virtual technology will be more mature and apply to diverse film art, which it can make a great contribution to further film in order to improve the influence of film art.
\end{abstract}

\section{Introduction}

Throughout the history of the development of film art, film-related technologies lurk from photograph to sound technology, and to color technology. Especially the modern virtual digital technology largely contributed to the progress of film art. With the modern science technologies increasingly developed, and continuous development and innovation of virtual reality technology, some advanced, cutting-edge, highly innovative imaging technologies emerged, let movie-making is no longer confined to the traditional sound realistic lighting and other movie image [1]. Otherwise, it obtains a kind of virtual film images that are beyond-reality. These images increase the infinite possibilities and the magical power that is beyond the reality, and making the movie screen from physical reality to virtual reality.

The virtual reality technology in the 1980's had begun to affect human life and product practice. So far, it applied maturely in all areas of practical life. Our film art under the era of sophisticated virtual image technology increasingly has also inevitably been affected from the virtual technology, and this kind of effect has great significance on film [2]. This paper lists many of the actual movie scenes from the aesthetic point of view of aesthetics, and we can clearly see how the virtual reality technology is applied to the film art through these real images and stills. We can make some further study about the impact of virtual technology to film art through by examining the perfect fusion of the film and the virtual technology that will create the intertwined visual effects of "virtual" and "reality".

\section{Film and virtual reality}

The relationship of film and virtual reality. In the history of film, the production of every unique film style as well as the debates towards each ideal transform are directly or indirectly correlated with the application of science and technology on the stage [3].

This phenomenon is particularly outstanding in modern and contemporary period. In the passing decades, the information science and technology has become an indispensable driving force for the innovation of film. "Virtual reality" is a special computer information technology, its advantages such as interaction, immersion and imagination can bring enormous potential in application field. This paper displays the author's thinking towards the application of virtual reality technology in film [4]. "Art and science are two kinds of means that the mankind get to know and change the world."However, the application of science and technology, at the end, still focuses on the material aspect of daily life [5]. The ultimate ones concerning spirit and psychology may only be solved by 
arts. The paper aims at arousing the artists' attention towards science and technology, and at the same time, leave more space for the reflection of art itself. Virtual reality as shown in Fig. 1 and 2.

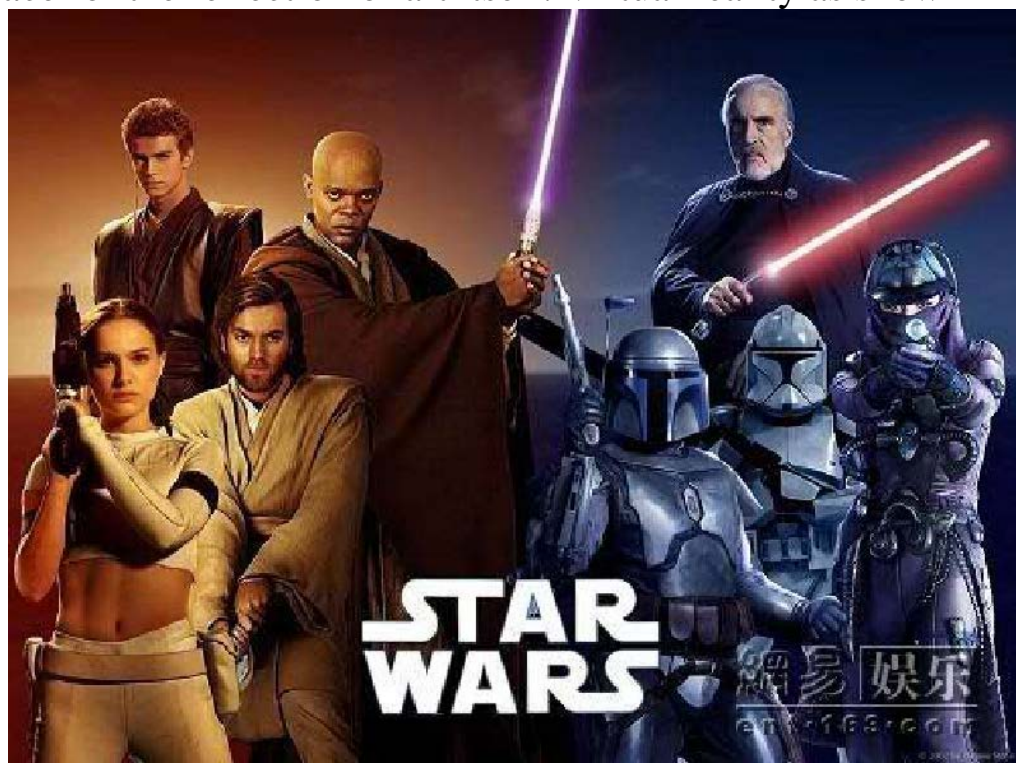

Fig. 1 Star wars

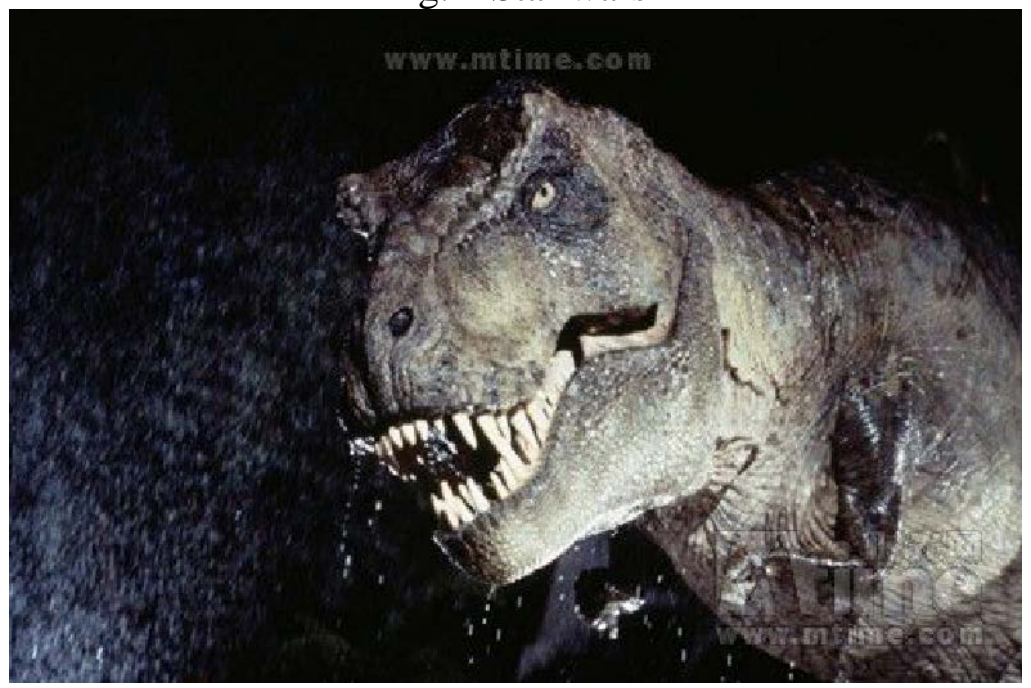

Fig. 2 Jurassic park

Art aesthetics and technology aesthetics in virtual reality system. Virtual Reality technology refers to computer-based, comprehensive utilization of three-dimensional graphics technology, multimedia technology, simulation technology and many other technologies. The result of the Virtual Reality technology is a "virtual world" with which people can interact [6]. It's a highly realistic simulation of the real-world. Virtual Reality technology is a comprehensive subject, especially the integration of virtualization technology and visual arts. In the integration the Virtual Reality works not only to show the side of technology, but also to show the side of art. These two aspects must integrate perfectly if we want to see the best Virtual Reality works. The Virtual Reality system is a technical term in aspect of construction, including hardware, software technology and other related technologies. But in aspect of performance, the Virtual Reality system is an artistic term. The Virtual Reality technology is used to create an immersion environment to satisfy the interaction between people and the environment, and the immersion environment is a result of the visual performance art.

\section{The creation and experience of aesthetics in virtual reality system}

People haven't been stopped to raise the question what is film and resulted in no perfect answer. Film has a particular close relationship with modern technology mainly because the technology promotes the development of film jumps at the same time as film itself. The century of film is actually the history indicating that film follows the enhancement of technology to be creative and changeable. 
Bazin's theory see to disintegrate after special good effect played a role in filmdom. Not only virtual actor but also virtual scene, more and more special good effect appeared on the screen. VR is shown in Geocentric travel 3D of Fig. 3.

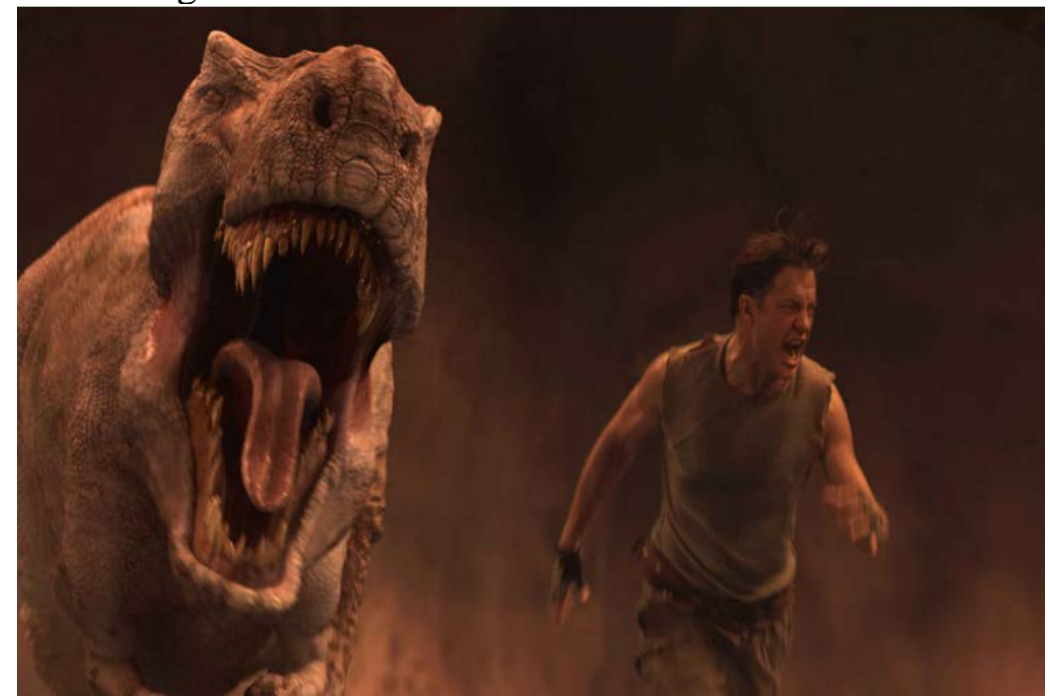

Fig. 3 Geocentric travel 3D

Then what special good effect influence on the film? Being advantage or disadvantage? Some people support special good effect because they think it improve the manner of making a film, and increase a lot of delight when people go to cinema. But the other people have the opposite opinion. Or change to another thing? First of all, the article analyzed the art aspect of the Virtual Reality system from two sides, the inheritance of the traditional art and the breakthrough to the traditional art. And then the article introduced the technical support to the breakthrough aspects. Secondly, the article analyzed the beauty of the Virtual Reality technology, including a number of key technologies involved and their Aesthetic property. Finally, based on previous research, the article advanced the guidance to the creation of the Virtual Reality system from the Aesthetic aspects. And then the article analyzed the performance of the Aesthetics-related law in Virtual Reality system. The theory analysis and actual application have been paid attention in this paper. The research of the paper can provide experiences to the creation of the Virtual Reality system from the Art Aesthetics and the Technology Aesthetics aspects. They believe special good effect weakens content of film, makes film be specious, and violates its nature to reflect reality. Live preview technology of Avatar is shown in Fig. 4. Motion capture of the Mummy Retures is shown in Fig. 5.

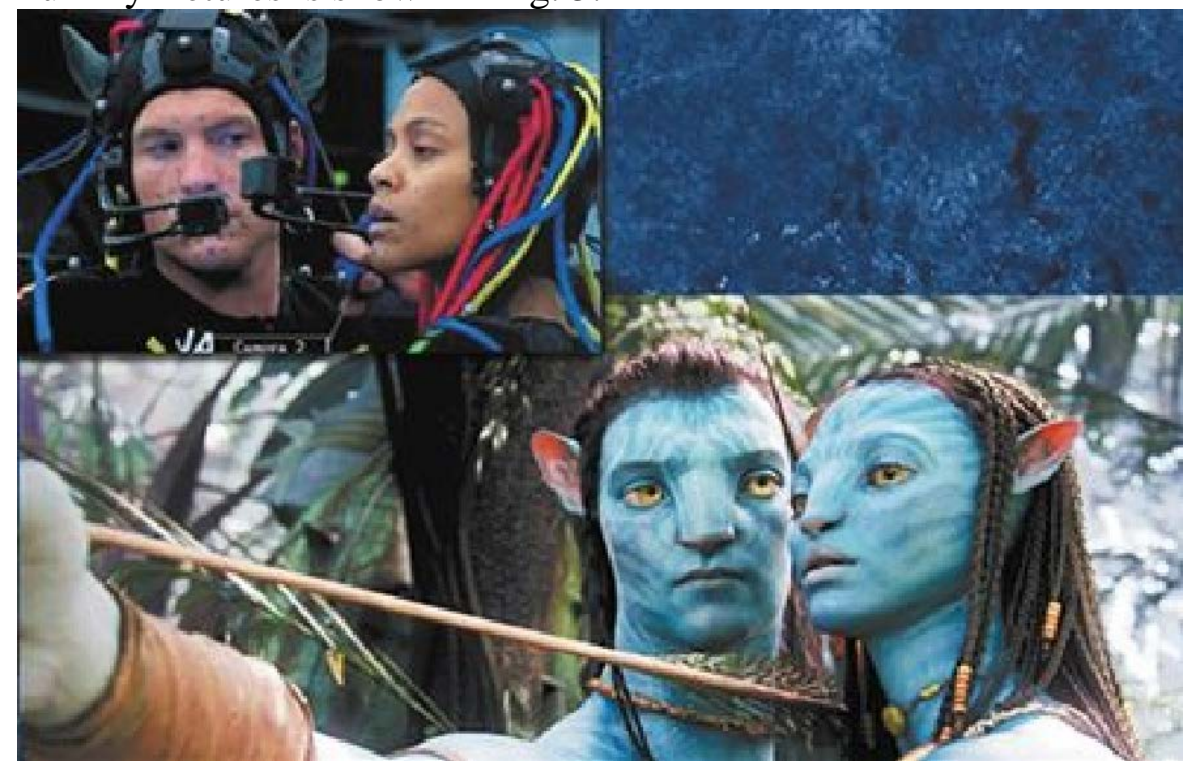

Fig. 4 Live preview technology of Avatar 


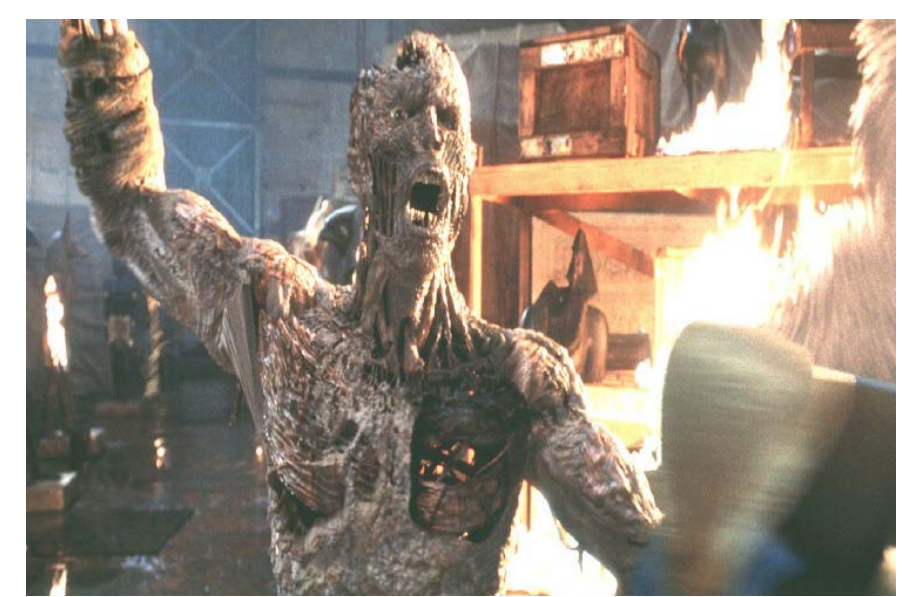

Fig. 5 Motion capture of the Mummy Retures

\section{Aesthetics performance in virtual reality system}

From the beginning of film making, we could tell that film is a special form of art. Unlike other forms of art which exists before the technology, however depends on the technology development for the reformation of its expression forms, the art of film making is born form technology. Without the technology of cinematography, there would not be the art of film making. As shown above, film is a kind of art which closely related to technology. Every innovation of technology has a revolutionary impact on film. Technology actively intervenes the development of film and promotes the world shaking changes to be true. Form silent to phonic, black and white to colorful, evolution of technology is questionably validated to enhance the huge leap of film expressive force. Thus, the progress of film could not be separated from technology which has a decisive function on film's development. Technology drives the evolution of film. Motion capture of the King Kong is shown in Fig. 6.

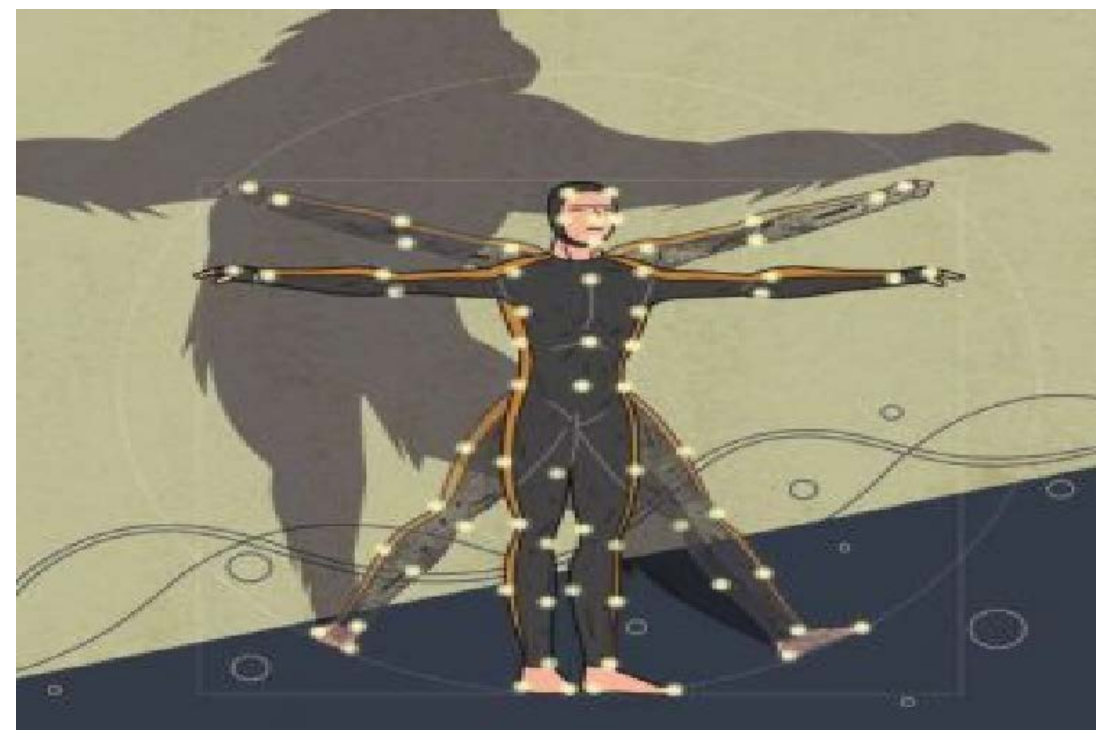

Fig. 6 Motion capture of the King Kong

Today, science and technology are developing at a great pace, the underlying Internet technology has brought further technical revolution, and all the laws of traditional industrial age will be remodeled. How can the traditional film media manage to survive in the future development of the New World? It's the most important issue that all the practitioners of television industry need to deal with. Bringing tremendous impact to the traditional television media, new technology also offers great opportunities. Creative applications of virtual reality technology in the field of television opened a door leading to the New World, in which both film technology and program planning are improving greatly. The traditional film media begins to embrace to a new age. Motion capture of Planet of the Apes Rise is shown in Fig. 7. 


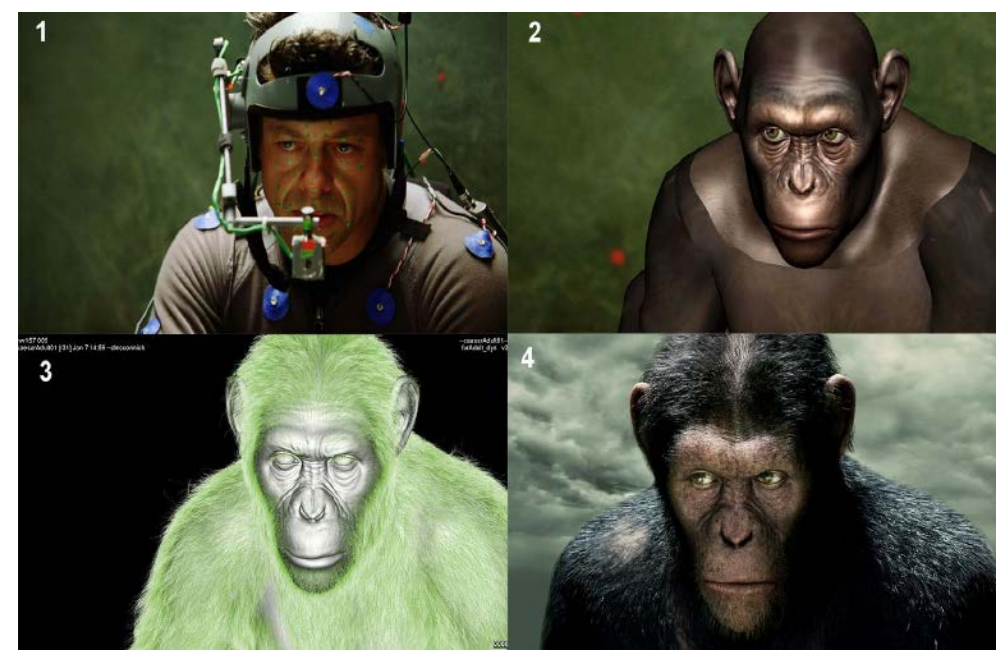

Fig.7 Motion capture of Planet of the Apes Rise

Virtual reality technology in television media can be broadly divided into two parts: a developed virtual studio technology, and a sophisticated developing virtual implant technology. Virtual studio technology has been basically popularized worldwide, while virtual implant technology is a brand new technology that virtual reality technology implied on film media, bringing new visual experience for the audience, and providing new tools and creative thoughts for television producers.

Virtual reality technology in the field of television, fundamentally speaking, is to express artistic idea and to create new television programs in the means of art as its core and technology as its carrier. Artistic thoughts runs through the entire process of the realization of technology, the two are inseparable.

\section{Conclusion}

This paper attempts to illustrate virtual reality technology film media applications through the analysis and comparison of different types of television programs in the virtual reality technology and the assumed role of different positioning, and to draw a conclusion about virtual reality technology applications in the film media. In doing so, this paper explores future trends of television media, and provides a theoretical reference for the majority of television media practitioners in the integration of traditional media.

\section{References}

[1] Wang X. Study on the Application of Virtual Reality in Landscape Design. Journal of Shandong Forestry Science and Technology, 2007.

[2] Luo P, Xiao-Feng H U, Guang-Ya S I. Study on Application of Virtual Reality in Strategic Decision Training. Computer Simulation, Vol. 26 (2009), No. 1, p. 24-27.

[3] Ai-Jun X U. A Theoretical Study on Application of Virtual Reality Technology in Higher Vocational Education. Journal of Southern Vocational Education, 2011.

[4] Shu-Bo L I. Theoretical Study on Application of Virtual Reality Technology in Vocational Education. Journal of Liaoning Higher Vocational, 2013.

[5] S Z, Bo. Virtual psycho-rheometry and its application (Sensory study on application of cosmetic base oil using virtual reality and flow analysis). Cosmetology Annual Report of Cosmetology, , Vol. 21 (2013) No. 4, p. 132-137.

[6] Jinlin Z, Manzhong L. The Application of Virtual Reality Technology in the Preservation of Mining and Metallurgy Culture in Huangshi Region[C]// International Conference on Optimization Design. 2010. 